\title{
AIDS and Economic Growth in South Africa ${ }^{1}$ \\ Rodney B W Smith \\ Department of Applied Economics, University of Minnesota, Saint Paul
}

\begin{abstract}
Morbidity and mortality effects are introduced into a three sector, Ramsey-type model of economic growth. The model is calibrated to South African national accounts data and used to examine the potential impact of HIV/AIDS on economic growth. Simulation results suggest a 10 per cent decrease in the size of the effective labour force would lead to a 10 per cent decrease in long-run (steady state) GDP levels. Similarly, a 10 per cent decrease in the number of labourers would lead to an 11 per cent drop in long-run GDP.
\end{abstract}

JEL 112, 015, 47

1

\section{Introduction}

Of the 36.1 million people living with HIV/ AIDS, 95 percent live in developing countries. Sub-Saharan Africa has 29.4 million people living with HIV/AIDS, of which ten million are young adults between the ages of 15 and 24, and almost 3 million children under 15 are living with HIV. Approximately 3.5 million new infections occurred in this region in 2002. HIV/ AIDS claimed the lives of an estimated 2.4 million Africans in 2002 (FAO, 2002).

The prevalence rate of HIV/AIDS is the percentage of the population infected with the disease. The national HIV prevalence rate of adults between 15 and 49 exceeds 30 per cent in four southern African countries.

Table 1

Adult HIV Prevalence Rates (ages 15 - 49)

\begin{tabular}{|l|c|}
\hline Country & Prevalence rate (\%) \\
\hline Botswana & 38.8 \\
\hline Lesotho & 31.0 \\
\hline Swaziland & 33.4 \\
\hline Zimbabwe & 33.7 \\
\hline
\end{tabular}

Source: UNAIDS, 2002.
The prevalence rates in other sub-Saharan countries include: Cameroon (11.8 per cent), Central African Republic (12.9 per cent), Zambia (20 per cent), Somalia (1 per cent) Uganda (5 per cent). In South Africa estimates of adult HIV prevalence range from 15 to 25 per cent (UNAIDS, 2002).

In many African countries HIV/AIDS began as an urban problem. During recent years, however, it has quickly become a greater threat in rural areas than in cities (UNAIDS, 2002). Of the 25 most-affected African countries, more than two thirds of the population live in rural areas (Bell, Devarajan \& Gersbach, 2003) with a disproportionate affect on economic sectors like agriculture, transportation and mining. As noted by Bell et al. (2003) and others, these industries are characterised by large numbers of mobile or migratory workers. Hence infections among workers in these industries are able to spill over into other regions as the workers move from one region to another. Since 1985 AIDS has killed over 7 million agricultural workers in the 25 hardest-hit countries in Africa, and it is estimated that 25 per cent (16 million workers) of these countries will die from the disease by 2020 . This is likely 
to impact food production, and possibly have adverse effects on aggregate gross domestic product (GDP), as currently over one-third of the GDP of the most-affected African countries is derived from agriculture (FAO, 2002).

Several studies have examined the likely impact of HIV/AIDS on economic growth. For example, Arndt and Lewis $(2000,2001)$ predict that relative to a no-AIDS scenario, annual aggregate GDP in South Africa would be 0.8 to 1.0 per cent lower in the presence of AIDS. AIDS could lead to a 0.56 to 1.08 per cent drop in the level of annual aggregate GDP growth between 1990 and 2025 (Over, 1992). During the same period, AIDS could lead to a 0.35 percent drop in per capita GDP. Sackey and Rarpala (2000) projected that aggregate GDP growth would drop from 4.0 per cent without AIDS to 2.4 per cent with the disease by 2010 and drop from 4.0 to 1.3 per cent in 2015 . Relative to a no-AIDS case, Bonnel (2000) estimates that over a twenty year period, a prevalence rate of 20 per cent would be accompanied by a 67 per cent drop in aggregate GDP levels.

Like others, Bell et al. (2003) argue AIDS destroys human capital, weakens mechanisms that generate human capital formation and decreases incentive for adults to invest in their children's human capital formation. They then explicitly model the impact of AIDS on human capital. Using an overlapping generation model calibrated to South Africa data, they examine the impact of AIDS on the average household income under various scenarios. In their baseline no-AIDS model, the expected annual growth in household income between 1990 and 2050 (two generations) was 1.46 per cent per year. Expected annual growth would be -1.2 per cent between 1990 and 2050, with the presence of AIDS and little or no intervention, and would be 1.22 per cent government intervention.

The models underlying the above predictions assume a subset of the following forces impacting on economic growth: (i) morbidity and mortality effects are impacted negatively; (ii) so are human and physical capital accumulation; (iii) savings and investment decline as expenditures get reallocated towards medical care; (iv) labour productivity may improve as AIDS-induced mortalities reduce the pressure of population on existing land and capital.

The above-mentioned studies take the following different approaches to ascertaining the impact of HIV/AIDS on economic growth: The studies by Bonnel (2000), Over (1992) and Sackey and Raparla (2000) combine demographic modeling with cross country econometric analysis to ascertain the impact of the disease and aggregate GDP. These studies focus on aggregate GDP levels and are not designed to investigate the impact of the disease on sub-sectors of the economy. The studies by Arndt and Lewis $(2000,2001)$ are based on a multi-sector computable general equilibrium (CGE) model, and look at the short- and intermediate-run impact of the disease on GDP growth. The Arndt and Lewis (2000, 2001) model is quite involved, and to simplify the analysis they assume the wage bill and the rate at which capital accumulates are exogenous. Although a very engaging study, the Bell et al. (2003) results are not easily related to the impact of AIDS on aggregate GDP growth or levels because the only productive resource in the model is labour augmented by human capital: there is no physical capital. Although these studies use different approaches to understanding the impact of HIV/AIDS on economic growth and development, they each lead to the same conclusion: HIV/AIDS is likely to affect economic negatively growth in subSaharan Africa.

In this paper, a simple, three sector Ramseytype model of a small open economy is resurrected, and calibrated to South African national accounts data. The model is then used to calculate the long-run impact of labour market shocks on aggregate GDP levels. Here, labour shocks are introduced simply by multiplying the country's labour endowment by a scalar whose value is between 0 and 1 . The scalar has one of two interpretations. In one interpretation it indexes the proportion of time an average labourer is healthy enough to work. For example, letting $\gamma$ represent the labour shock parameter, if $\gamma=0.95$, a worker on average does not report to work 5 per cent of the time. This is the effective labour or morbidity 
interpretation. Under the morbidity interpretation HIV/AIDS is viewed as a disease that decreases the amount of time on the job, impacting the marginal product of a labourunit. In the other interpretation the parameter represents the proportion of individuals who die as a result of the disease. Again, letting $\gamma$ represent the parameter, if $\gamma=0.95$ then 5 per cent of the workforce dies as a result of the disease. This is the mortality interpretation.

One basic result of the exercise is that when the labour shock is viewed purely as a morbidity problem, a 1 per cent drop in the size of the effective labour force leads to a 1 per cent drop in the level of long-run aggregate GDP. Likewise, when viewed purely as a mortality problem, a 1 per cent drop in the size of the labour force also leads to a 1 per cent drop in the level of longrun aggregate GDP. When there is both a morbidity and a mortality problem, a 1 per cent drop in the size of the labour force and a 1 per cent drop in the effective labour force lead to a 2 per cent drop in the level of long-run aggregate GDP. This result, and the others reported later, should be viewed as crude, back-of-theenvelope calculations of the disease's economic impacts. Note, given the manner in which the data is normalised, no attempt is made to determine per capita GDP levels.

The model's simplicity carries with it several problems. For instance, potential health expenditures could possibly affect the rate at which capital accumulates, and hence exacerbate the decrease in the long-run level of GDP. A few more of the model's shortcomings are discussed in the conclusion, along with a brief overview of current attempts by the author and others to overcome some of these shortcomings.

The paper is organised as follows. The Ramsey-type model is presented in the next section. This model has the standard features one would expect in a general equilibrium model. There are three sectors: endogenous wages; endogenous rates of return to capital; and intertemporal optimising behavior savings. In addition, it adds a set of parameters whose objective it is to represent labour force shocks. Section 3 presents the results of calibrating the model to South African data and simulating the impact of HIV/AIDS on economic growth. The last section concludes and outlines a few additional features to be included in future work. The interested reader can refer to the appendix for a formal definition of intertemporal and long-run (steady state) equilibrium.

\section{2}

\section{Basic model}

We now describe a model economy endowed with land, labour and capital that produces three types of output: agriculture, manufacturing and services. The agricultural and manufacturing goods are traded goods, while services are not traded. Because the country's volume of production is relatively small, that, together with export decisions, has no appreciable effect on world prices.

\subsection{Production}

The agricultural, manufacturing, and service goods are denoted by $Y_{a}, Y_{m}$ and $Y_{s}$ respectively, where $\left(Y_{a}, Y_{m}, Y_{s}\right)=Y \varepsilon \mathbf{R}_{+}^{3}$. These goods are produced with three productive inputs: land, labour and capital, denoted respectively by $\bar{T}$, $L$, and $K$, where $(\bar{T}, L, K)=X \varepsilon \mathrm{R}_{+}^{3}$. Land is typical to agricultural production, while capital and labour are mobile across sectors. The output vector $Y$ is produced with endowment $X$ using a constant return to scale (CRS) technology represented by the producible output set $\mathbf{Y}(X)$ $=\{Y: X$ can produce $Y\}$.

Let $L_{a}, L_{m}$, and $L_{s}$ denote the respective levels of labour allocated to agriculture, manufacturing, and services; and $K_{a}, K_{m}$, and $K_{s}$ denote the respective levels of capital allocated to agri-culture, manufacturing, and services. To introduce the labour shock we multiply $L$ and/ or $L_{j}$ by the parameter $\gamma_{1}, \gamma_{2} \varepsilon(0,1]$. See below for further discussion of $\gamma_{i}$. Assuming production is nonjoint in inputs, with the labour shock parameter, technology can be represented by $\mathbf{Y}(L, \bar{T}, K)=\left\{\left(Y_{a}, Y_{m}, Y_{s}\right): Y_{a} \leq F^{a}\left(\gamma_{1} L_{a}, K_{a}\right) T\right.$, $Y_{m} \leq F^{m}\left(\gamma_{1} L_{m}, K_{m}\right), Y_{s} \leq F^{s}\left(\gamma_{1} L_{s}, K_{s}\right) ; \gamma_{2} L \geq L_{a}+$ $\left.L_{m}+L_{s}, K \geq K_{a}+K_{m}+K_{s}\right\}$,

where $F^{a}, F^{m}$, and $F^{s}$ are the production functions for agriculture, manufacturing, and services 
respectively. We assume each production function is increasing and strictly concave in each argument. Here, $\gamma_{1}$ is the morbidity parameter and $\gamma_{2}$ is the mortality parameter.

\section{Table2}

Labour shock interpretations

\begin{tabular}{|l|c|c|}
\hline & $\gamma_{1}=1$ & $\gamma_{1} \varepsilon(0,1)$ \\
\hline$\gamma_{1}=1$ & $\begin{array}{c}\text { No labour market } \\
\text { shock }\end{array}$ & $\begin{array}{c}\text { Pure morbidity } \\
\text { interpretation }\end{array}$ \\
\hline$\gamma_{2} \varepsilon(0,1)$ & $\begin{array}{c}\text { Pure mortality } \\
\text { interpretation }\end{array}$ & $\begin{array}{c}\text { Morbidity } \\
\text { and mortality }\end{array}$ \\
\hline
\end{tabular}

The per-unit minimum cost of the manufacturing and service output are

$C^{m}\left(w, r, \gamma_{1}\right) \equiv \min _{\left\{L_{m}, K_{m}\right\}}\left\{w L_{m}+r K_{m}: 1 \leq F^{m}\left(\gamma_{1} L_{m}, K_{m}\right)\right\}$

$C^{s}\left(w, r ; \gamma_{1}\right) \equiv \min _{\left\{L_{s}, K_{s}\right\}}\left\{w L_{s}+r K_{s}: 1 \leq F^{s}\left(\gamma_{1} L_{s}, K_{s}\right)\right\}$

and the maximum net GDP (rents) in the agricultural sector is given by

$G^{a}\left(p_{a} w, r, \gamma_{1}\right) T \equiv \max _{\left\{L_{a}, K_{a}\right\}}\left\{p_{\mathrm{a}} F^{\mathrm{a}}\left\{\gamma_{1} L_{a}, K_{a}\right) T-w L_{a}-r K_{a}\right\}$.

Here, $w$ is the wage rate, $r$ is the rental rate to capital, and $p_{a}$ is the per unit price of the agricultural good (normalised with respect to $p_{m}$, the price of manufacturing). Under our assumptions, $G^{a}$ is the per-unit land rental payment. The corresponding cost and agricultural GDP functions under the mortality interpretation.

\subsection{Households}

Assume there are $L$ identical, infinitely occupied households. A household earns income by selling labour at wage rate $w$, renting capital services at rate $r$ and renting land at rate $\tau$. The household then allocates its income between savings and consumption.

Represent the household's utility at time $t$ by $\mathbf{u}(t) \varepsilon \mathrm{R}_{+}$, and represent its intertemporal utility function by

$\mathrm{U}=\int_{0}^{\infty} \log (\mathbf{u}(t)) e^{-p t} d t$.

Suppressing the time argument, the minimum cost per household of achieving utility $\mathbf{u}$ is given by the expenditure function

$E\left(p_{a}, p_{s}, \mathbf{u}\right)=\mu\left(p_{a}, p_{s}\right) \mathbf{u} \equiv \min _{\{q\}}\left\{\left(q_{m}+p_{a} q_{a}+\right.\right.$ $\left.\left.p_{s} q_{s}\right) \mid \mathbf{u} \leq u\left(q_{a}, q_{m}, q_{s}\right)\right\}$.
Here, $p_{s}$ is the price of the non-traded service goods (normalised with respect to $p_{m}$, the price of manufacturing), and $u\left(q_{a}, q_{m}, q_{s}\right)$ is the instantaneous utility associated with consumption bundle $\left(q_{a}, q_{m}, q_{s}\right) \varepsilon \mathrm{R}_{+}^{3} ; q_{a}, q_{m}$, and $q_{s}$ are the per-capita levels of agricultural, manufacturing, and non-health service consumption.

The intertemporal budget constraint of the household is given by

$$
\dot{K}=w+r K+\tau T-\mu\left(p_{a}, p_{s}\right) \mathbf{u} \text {. }
$$

Suppressing the time argument, given preferences and flow budget constraint (1), the household's present value Hamiltonian is

$J=\log [\mathbf{u}]+v\left\{w+r K+\tau \mathbf{T}-\mu\left(p_{a}, p_{s}\right) \mathbf{u}\right\}$,

where the costate variable $v$ is the shadow value of additional income. The household's optimisation problem includes one state variable, $K$, and one control variable, $\mathbf{u}$.

Let $E_{u}=\partial E / \partial \mathbf{u}$. The utility maximising choice for an interior solution satisfies the following necessary conditions:

(i) $\begin{aligned} \frac{\partial J}{\partial \mathbf{u}} & =\frac{1}{\mathbf{u}}-v \mu\left(p_{a}, p_{s}\right)=0, \\ \dot{v} & =p v-\frac{\partial J}{\partial k}=(\rho-r) v,\end{aligned}$

(ii) the equation of motion (1), and

(iii) the transversality condition

$$
\lim _{t \rightarrow \infty}[v(t) \dot{K}(t)]=0
$$

Using expression (2) we solve for $v$, take the time derivative of the resulting expression and then make relatively straightforward substitutions into expression (3) to get the Euler condition:

$$
\frac{\dot{\mathbf{u}}(t)}{\mathbf{u}(t)}+\frac{\mu_{p s}}{\mu} \dot{p}_{s}=r(t)-\rho .
$$

A definition of the competitive equilibrium for the above models is presented in the appendix, as is a characterisation of the equilibrium.

\subsection{Calibration results}

The production technologies in the calibrated economy are assumed approximated by the following functions: 
$y_{a}=\left(\hat{\gamma}_{1} l_{a}\right)^{\beta_{1}}\left(k_{a}\right)^{\beta_{2}} T^{1-\beta_{1}-\beta_{2}}$

$y_{m}=\left(\hat{\gamma}_{1} l_{m}\right)^{\alpha}\left(k_{m}\right)^{1-\alpha}$

$y_{s}=\left(\hat{\gamma}_{1} l_{s}\right)^{\eta}\left(k_{s}\right)^{1-\eta}$,

where the scalar coefficients $\beta_{j} \varepsilon(0,1), j=1,2,3$, and $a_{j}, \eta_{j} \varepsilon(0,1), j=1,2$ are cost shares. For example, $\alpha$ is labour's share in the cost of producing the manufacturing goods, while $\beta_{2}$ is capital's share in the cost of producing agriculture. Constant returns to scale requires $\beta_{1}+\beta_{2}+\beta_{3}=\alpha_{1}+\alpha_{2}=\eta_{1+} \eta_{2}=1$. Consumer preferences are represented by

$u\left(q_{a}, q_{m}, q_{s}\right)=\left(q_{a}\right)^{\phi_{1}}\left(q_{m}\right)^{\phi_{2}}\left(q_{s}\right)^{\phi_{3}}$,

where the scalar coefficients $\phi_{j} \varepsilon(0,1), j=1,2,3$ are consumption share coefficients, where $\phi_{1}+$ $\phi_{2}+\phi_{3}=1$. Here, $\phi_{1}$ is the share of aggregate South African income spent on agricultural consumption.

Using South African national accounts data from the International Food Policy Research Institute (1993), the following cost (production) shares were derived:
Table 3

Production cost shares

\begin{tabular}{|l|c|c|c|}
\hline & Labour & Capital & Land \\
\hline Agriculture & $\beta_{1}=0.371$ & $\beta_{2}=0.50$ & $\beta_{3}=0.129$ \\
\hline $\begin{array}{l}\text { Manu- } \\
\text { facturing }\end{array}$ & $\alpha_{1}=0.522$ & $\alpha_{2}=0.478$ & - \\
\hline Services & $\eta_{1}=0.595$ & $\eta_{2}=0.405$ & - \\
\hline
\end{tabular}

Consumption shares are also derived from South African national accounts data, and are given by

$\phi_{1}=0.0546, \phi_{2}=0.3305, \phi_{3}=0.6149$.

With no labour market shocks, i.e., $\gamma_{1}=\gamma_{2}=1$, long-run GDP is projected to be equal to R572,077 million. Also, in each scenario for both the mortality and morbidity models, the price of the non-traded goods drops by about 20 per cent. Given that we normalise $L$, the following results can be viewed in level terms. We first discuss the relationship between morbidity and long-run economic performance. Then, results from the mortality model are presented, along with a brief comparison of the morbidity and mortality models. Table 4 relates effective labour rates to long-run GDP.

Table 4

Effective labour rates

\begin{tabular}{|l|c|c|c|c|c|c|c|c|}
\hline & \multicolumn{2}{|c|}{$\begin{array}{c}\text { Manufacturing } \\
(\mathbf{1 6 2 , 5 1 8})^{+\ddagger}\end{array}$} & \multicolumn{2}{c|}{$\begin{array}{c}\text { Services } \\
(\mathbf{2 4 9 , 1 8 6})^{\dagger \neq}\end{array}$} & \multicolumn{2}{c|}{$\begin{array}{c}\text { Capital } \\
(\mathbf{3 , 1 0 3 , 0 0 0})^{\dagger \ddagger}\end{array}$} & \multicolumn{2}{c|}{$\begin{array}{c}\text { GDP } \\
(\mathbf{4 2 6 , 1 3 3})^{+\ddagger}\end{array}$} \\
\hline$\gamma_{\mathbf{1}}$ & Value $^{\ddagger}$ & \% change & Value $^{\ddagger}$ & \% change & Value $^{\ddagger}$ & \% change & Value $^{\ddagger}$ & \% change $^{\text {ch }}$ \\
\hline 1.0 & 224,349 & & 339,811 & & $6,161,820$ & & 567,722 & \\
\hline 0.9 & 201,960 & -9.98 & 304,062 & -10.52 & $5,562,060$ & -9.73 & 509,585 & -10.24 \\
\hline 0.8 & 179,572 & -19.96 & 268,313 & -21.04 & $4,962,310$ & -19.47 & 451,448 & -20.48 \\
\hline 0.7 & 157,184 & -29.94 & 232,564 & -31.56 & $4,362,550$ & -29.20 & 393,310 & -30.72 \\
\hline
\end{tabular}

$\dagger$ Values in parenthesis are calibrated base period values. $\ddagger$ Million South African Rand

A quick inspection of Table 4 shows the elasticity of long-run GDP with respect to $\gamma_{1}$ is about 1 , i.e., a 10 per cent drop in $\gamma$ leads to (about) a 10.24 per cent drop in the level of long-run GDP (relative to the case where $\gamma_{1}=$ $\gamma_{2}=1$ ). Of course, since there is no attempt to determine the length of time required to reach the steady state, it is not possible to determine the impact of a 10 per cent drop in $\gamma_{1}$ on short and intermediate run GDP growth rates. Observe, that at $\gamma_{1}=0,7$ long-run GDP is equal to 393310 - a level less than the initial period's GDP of 426133 . Hence, a large enough morbidity problem can trigger a scenario in 
which short or intermediate run GDP growth is negative.

A major factor underlying the decrease in long-run GDP is that the long-run stock of capital falls as morbidity levels increase. As morbidity levels increase, the marginal product associated with a given level of labour falls. With the marginal product of labour falling, the value of an additional unit of capital falls, hence decreasing the incentive to invest. In such a case investment incentives fall, and less capital is accumulated in the short and intermediate run, hence leaving the economy with a smaller capital stock in the long run. Indeed, Table 4 shows that a 10 per cent increase in morbidity leads to a 9.7 per cent drop in the long-run stock of capital.

Table 4 also shows the impact of an increase in morbidity is about the same in both the manufacturing and service sector: with a 10 per cent increase in morbidity leading to about a 10 per cent drop in output from the two sectors. Figure 1 presents a plot of agricultural land rents as a percent of aggregate GDP against morbidity levels, and shows agriculture's share of longrun GDP increases slightly as morbidity levels increase.

\section{Figure 1}

Morbidity effects and agricultural income shares

AgShare

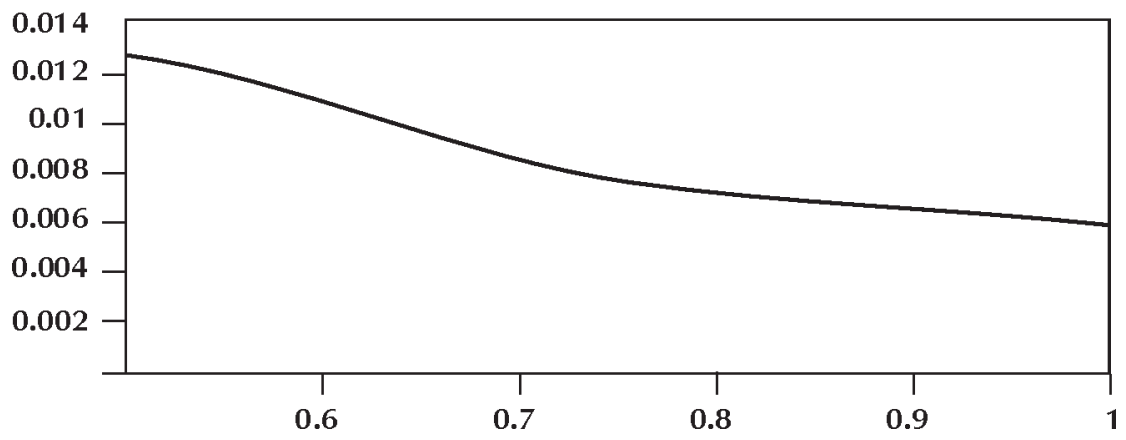

Figure 1 suggests with no morbidity problems, agriculture would comprise a slightly smaller share of aggregate income in the long run $(0.7$ per cent). As morbidity problems increase, agriculture's share of aggregate income increases to 1.25 per cent. Although not plotted here, manufacturing's share of aggregate income increases from 39.5 per cent with no morbidity to 49.5 per cent when $\gamma_{1}=0.7$, and services' share drops from 59.8 per cent with no morbidity to 49.6 per cent when $\gamma_{1}=0.7$. This result occurs because the service sector is the most labour intensive sector in the economy, and morbidity increases the per unit cost of labour, increasing wages from $w$ to $w / \gamma_{1}>w$; or, viewed another way, morbidity acts like a labour tax equal to $\frac{1-\gamma_{1}}{\gamma_{1}}$. The "wage tax" introduces Stolper-Samuelson type effects on the service sector.
The wage bill as a function of $\gamma_{1}$ is given by $w(y)=329477^{*} \gamma_{1}$ implying the total payment to labour is proportional to the base aggregate GDP. In the base year, labour's share of aggregate income was 57 per cent. In the simulations, labour's share remained between 58 per cent and 59 per cent, increasing slightly from 58.0 per cent to 58.6 per cent as $\gamma_{1}$ falls. Given the tax interpretation, morbidity introduces a distortion that slightly favors labour. As an aside, the simulations examine the case where there is a single representative agent, hence not much can be said directly about the likely impact of HIV/AIDS on poverty. With aggregate income falling, however, and given the share of income received by labour remains relatively constant, the result does not augur well for the poor. 
Table 5 suggests the impacts of mortality on long-run GDP are similar to that of morbidity: a 10 per cent drop in the labour endowment is accompanied by a 9.95 per cent drop in the level of long-run GDP (again, this is relative to the case where $\left.\gamma_{1}=\gamma_{2}=1\right)$. As mortality levels increase, the marginal product of capital falls, decreasing the incentive to invest. Again, in such a case investment incentives fall, less capital is accumulated in the short and intermediate run, and the economy ends up with a smaller stock of capital in the long run. Table 5 shows that under mortality a 10 per cent increase in morbidity leads to a 9.1 per cent drop in the long-run stock of capital.

Table 5

Impacts of mortality

\begin{tabular}{|c|c|c|c|c|c|c|c|c|}
\hline \multirow[b]{2}{*}{$\gamma_{1}$} & \multicolumn{2}{|c|}{$\begin{array}{l}\text { Manufacturing } \\
\qquad(162,518)^{+\ddagger}\end{array}$} & \multicolumn{2}{|c|}{$\begin{array}{c}\text { Services } \\
(249,186)^{\dagger \neq}\end{array}$} & \multicolumn{2}{|c|}{$\begin{array}{c}\text { Capital } \\
(3,103,000)^{+\neq}\end{array}$} & \multicolumn{2}{|c|}{$\begin{array}{c}\text { GDP } \\
(426,133)^{t \ddagger}\end{array}$} \\
\hline & Value $^{\ddagger}$ & $\%$ change & Value $^{\ddagger}$ & $\%$ change & Value $^{\ddagger}$ & $\%$ change & Value $^{*}$ & $\%$ change \\
\hline 1.0 & 224,349 & & 339,811 & & $6,161,820$ & & 567,722 & \\
\hline 0.9 & 215,276 & -4.04 & 292,376 & -13.96 & $5,600,840$ & -9.10 & 511,214 & -9.95 \\
\hline 0.8 & 206,202 & -8.08 & 244,940 & -27.92 & $5,039,870$ & -18.21 & 454,705 & -19.90 \\
\hline 0.7 & 197,129 & -12.13 & 197,505 & -41.88 & $4,478,900$ & -27.31 & 398,197 & -29.86 \\
\hline
\end{tabular}

${ }^{+}$Values in parenthesis are calibrated base period values $\ddagger$ Million South African Rand

Although the morbidity effects tend to be distributed evenly across sectors, the effect of increased rates of mortality is more pronounced in the service sector than in agriculture and manufacturing. Table 5 shows the impact of mortality on the service sector is over three times that on manufacturing, and Figure 2 shows the share of services in aggregate GDP drops significantly as AIDS mortality rates increase. Here, we see Rybczynski-type effects arising from the drop in the sise of the long-run labour force, with the labour intensive service sector losing labour to manufacturing.

\section{Figure 2}

Mortality effects and sectoral income shares

\section{Shares}

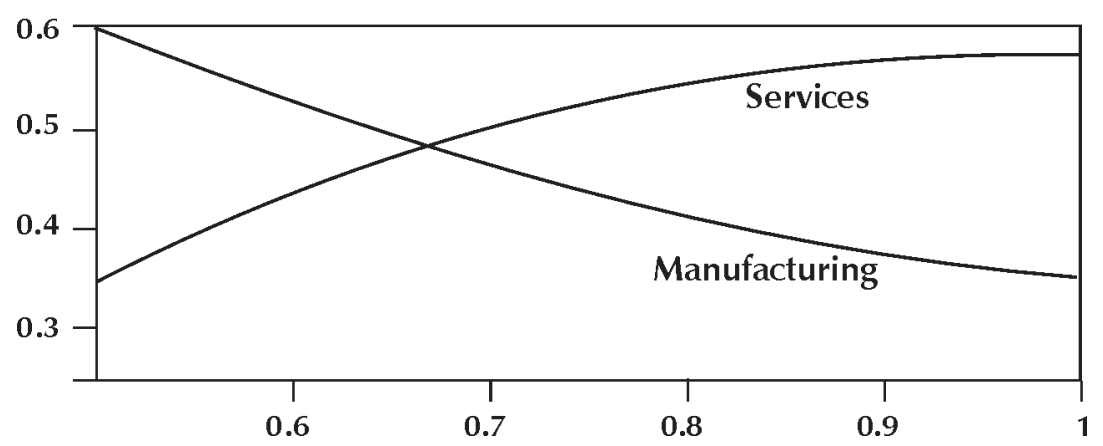


Given that morbidity impacts the service sector more than manufacturing and agriculture, HIV/ AIDS policy debates will likely include discussions over whether the government should subsidise anti-retroviral drug prices. Lobbyists for manufacturing interests would push for government subsidies on anti-retroviral drugs, while the service sector might stress investing public funds into HIV/AIDS awareness education.

Although not reported here, the model also examined scenarios with both morbidity and mortality. Under these scenarios, long-run GDP falls about one percent for each one percent increase in morbidity and/or mortality. For example, if both morbidity and mortality were at 10 percent $\left(\gamma_{1}=\gamma_{2}=0,9\right)$, long-run GDP would be about percent lower than GDP with no HIV and AIDS.

3

\section{Conclusion}

The objective of this study was to investigate the potential morbidity and mortality impacts of HIV/AIDS on long-run aggregate GDP, and on income distribution and production patterns. Morbidity and mortality parameters were introduced into a three sector, Ramsey-type model, and simulations conducted. The model was calibrated to 1993 South African national accounts data, and the following results were found: (i) long-run GDP levels fell by about 1 percent for each one percent loss in time spent working; (ii) long-run GDP levels fell a little less than 1 percent for each one percent loss in the labour force due to death; (iii) the long stock of capital falls less than one percent for each one percent increase in morbidity and falls a little more than 0.9 percent for each one percent increase in mortality; and (iv) under mortality, service sector output drops three times as much as manufacturing. The analysis also suggests negative GDP growth scenarios are possible, but such outcomes are not likely unless morbidity and/or mortality levels as modelled here are 30 per cent or more.

As noted in the introduction, the results of this study should be viewed as preliminary, "back-of-the-envelope" results, as the model has proven to have several shortcomings. First, analysis of the transition path needs to be conducted. After all, the model is set up to analyse the short, intermediate, and long-run impact of HIV/AIDS on economic growth. Second, regarding morbidity, the model looks at the impact on long-run GDP only if, say, on average, workers spend one per cent less time working because of HIV/AIDS. The model does not, however, link HIV/AIDS prevalence rates to morbidity levels. The same can be said about death rates. The model also says nothing about the possible impact of health expenditures on long-run GDP. Health expenditures would likely affect the rate at which capital accumulates, and hence, exacerbate the decrease in long-run GDP levels. On the other hand, health expenditures would likely decrease morbidity rates and mortality. These two opposing forces suggest there might be an optimal level of investment in AIDS treatment. Hence, linking (endogenising) mortality with health expenditures is a natural next step in which to take the above research. Another important direction in which to take future research is to introduce population and prevalence dynamics into the model. Linking prevalence and population dynamics is another way to endogenise mortality.

\section{Endnote}

The author thanks Terry Roe for many helpful comments, and for providing the national accounts data upon which the model simulations are based.

\section{References}

1 ARNDT, C. \& LEWIS, J. (2000) "The macro implications of HIV/AIDS in South Africa: A preliminary assessment", South African Journal of Economics, 68(5): 856-87.

2 ARNDT, C. \& LEWIS, J.D. (2001) "The HIV/ AIDS pandemic in South Africa: Sectoral impacts and unemployment", Journal of International Development, 13: 427-49.

3 BELL, C.S.; DEVARAJAN \& GERSBACH, H. (2003) The Long-run Economic Costs of AIDS: 
Theory and an Application to South Africa, World Bank: Washington DC.

4 BONNEL, R. (2000) HIVIAIDS: Does it Increase or Decrease Growth in Africa? ACT, Africa Department, World Bank: Washington DC.

5 FAO (2002) "HIV/AIDS a rural issue", http:// www.fao.org/Focus/ E/aids/aids1-e.htm.

6 OVER, A.M. (1992) "The macroeconomic impact of AIDS in Sub-Saharan Africa", AFTPN Technical Working Paper 3, Population, Health and Nutrition Division, Africa Technical Department, World Bank: Washington, DC.

7 SACKEY, J. \& RAPARLA, T. (2000) "Lesotho: The development impact of HIV/AIDS Selected issues and options", AFTM1 Report No. 21103. LSO, Macroeconomic Technical Group, Africa Region, World Bank: Washington, DC.

8 UNAIDS (2002) "Fact sheet 2002", http:// www.unaids.org/en/media/fact+sheets.asp.

\section{Appendix A}

\section{A.1 Defining the competitive equilibrium}

At each point in time both intertemporal and intra-temporal equilibrium conditions must be satisfied. Intra-temporal equilibrium requires that households maximise utility, firms earn zero profits, labour and capital markets clear, Walras' law is satisfied, and the Euler and transversality conditions hold.

Define the following set, $\hat{\mathbf{Y}}\left(L, T, K, \gamma_{1}, \gamma_{2}\right) \equiv$ $\mathrm{Y}\left(L, T, K: \gamma_{1}, \gamma_{2}\right)$. A time $t$ production plan $Y(t)$ $=\left(Y_{a}(t), Y_{m}(t), Y_{s}(t)\right)$ is feasible if $Y(t)$ $\varepsilon \mathbf{Y}(L, T, K, \gamma, \hat{\gamma})$. Furthermore, let $\mathrm{u}(\mathrm{t}) \varepsilon \mathbf{U}$ denote the household's (feasible) time $t$ consumption plan. A sequence of consumption plans is feasible if for each $t \varepsilon[0, \infty), \mathbf{c}(t) \varepsilon C$, and a sequence of production plans is feasible if for each $t \varepsilon[0, \infty), Y(t) \varepsilon \hat{\mathbf{Y}}\left(L, T, K, \gamma_{1}, \gamma_{2}\right)$.

Definition: Given $\left(\gamma_{1}, \gamma_{2}\right)$ and initial condition $k(0)=k_{0}$, competitive equilibrium is a sequence of prices $\left\{p_{a^{\prime}} p_{s}(t), w(t), r(t), \tau(t)\right\}_{t \varepsilon[0, \infty)}$ feasible consumption plans $\{u(t)\}_{t \varepsilon[0, \infty)}$ and feasible production plans $\left\{Y_{a}(t), Y_{m}(t), Y_{s}(t)\right\}_{t \varepsilon[0, \infty)}$, such that at each $t$ : (i) given prices $\left(p_{a} p_{s}(t), w(t), r(t)\right)$ the manufacturing and service sectors earn zero profits

$1=C^{m}\left(w(t), r(t), \gamma_{1}\right)$

$p_{s}(\mathrm{t})=C^{s}\left(w(t), r(t), \gamma_{1}\right)$, the service goods market clears

$E_{p_{s}}\left(p_{a}, p_{s}(\mathrm{t}), \mathbf{u}(t)\right)=Y_{s}(t)$

and labour and capital markets clear

$\gamma_{2} \leq-G_{w}^{a}\left(p_{a}, w(t), r(t), \gamma_{1}\right) T+C_{w}^{m}\left(w(t), r(t), \gamma_{1}\right)$

$Y_{m}(t)+C_{w}^{s}\left(w(t), r(t), \gamma_{1}\right) Y_{s}(t)$

$K(t) \leq-G_{r}^{a}\left(p_{a}, w(t), r(t), \gamma_{1}\right) T+C_{r}^{m}(w(t), r(t)$,

$\left.\gamma_{1}\right) Y_{m}(t)+C_{r}^{s}\left(w(t), r(t), \gamma_{1}\right) Y_{s}(t)$

(ii) the consumption plan $\mathbf{u}(t)$ maximises household utility given the budget constraint

$K=w(t)+r(t) K(t)+\tau(t) T-E\left(p_{a}, \mathbf{u}(t)\right) ;$

(iii) Walras' Law holds

$\left[Y_{m}(t)-q_{m}(t)-K(t)\right]+p_{a}\left[Y_{a}(t)-q_{a}(t)\right]=0$;

and (iv) Euler's condition (5) and the transversality condition (6) hold.

The above definition says, given the exogenous prices and factor endowments, the model must satisfy four sets of restrictions: (i) Constant returns to scale and no sector specific factors in manufacturing and services, require that zero economic profits be earned in the two sectors. The supply of the non-traded service goods must be equal to its demand, and the supply of labour and capital must be equal to their respective aggregate demands; (ii) consumption decisions must maximise utility, given available income. (iii) the value of goods imported must equal the value of goods sold (net savings); and (iv) the value of an additional unit of income consumed must be equal to the value of an additional unit of consumption in the future (income saved).

\section{A.2 Calibrating the steady state}

In the steady state, $\dot{K}=\dot{E}=0$. First, $\dot{E}=0$ implies $r^{* *}=\rho$. Suppressing the time argument, equations (6) and (7) are now:

$1=C^{m}\left(w, \rho, \gamma_{1}\right)$

$p_{s}=C^{s}\left(\mathrm{w}, \rho, \gamma_{1}\right)$,

implying $\mathrm{w}^{* *}=\mathrm{w}\left(\rho, \gamma_{1}\right)$ and $p_{s}^{* *}=p_{s}\left(\rho, \gamma_{1}\right)$.

Substituting into expressions (9) and (10):

$\gamma_{2}=-G_{w}^{a}\left(p_{a}, w^{* *}, \rho, \gamma_{1}\right) T+C_{w}^{m}\left(w^{* *}, \rho, \gamma_{1}\right) Y_{m}$ $+C_{w}^{s}\left(w^{* *}, \rho, \gamma_{1}\right) Y_{s}$

$K=-G_{r}^{a}\left(p_{a}, w^{* *}, \rho, \gamma_{1}\right) T+C_{r}^{m}\left(w^{* *}, \rho, \gamma_{1}\right) Y_{m}+$ $C_{r}^{s}\left(\mathrm{w}^{* *}, \rho, \gamma_{1}\right) Y_{s}$ 
which combined with $Y_{m}^{*}+G^{a}\left(p_{a}, \mathrm{~W}^{* *}, \rho, \gamma_{1}\right) T=E_{p_{a}}\left(p_{a}, p_{s}^{* *}, \mathbf{u}(t)\right)+$
$E_{p_{m}}\left(p_{a}, p_{s}^{* *}, \mathbf{u}(t)\right)$

yields $Y_{m}^{*}=Y_{m}\left(\rho, \gamma_{1}, \gamma_{2}\right), Y_{s}^{*}=Y_{s}\left(\rho, \gamma_{1}, \gamma_{2}\right)$, and $K^{*}=K\left(\rho, \gamma_{1}, \gamma_{2}\right)$.

The values $\Omega=\left(r^{* *}, w^{* *}, p_{s}^{* *}, \mathbf{u}^{* *}, Y_{m}^{* *}\right.$, $\left.Y_{s}^{* *}, \gamma_{1}, \gamma_{2}\right)$ can be used to recover any remaining steady-state variables, e.g.,

$Y_{a}^{* *}=G_{p_{a}}^{a}\left(p_{a}, w^{* *}, \rho, \gamma_{1}\right) T$.
As noted in the introduction, a simple albeit crude way to introduce HIV/AIDS into the Ramsey model is to assume the disease decreases the amount of time an individual spends working, i.e., impacts the effective labour supply of infected individuals. In such a case, the labour market clearing condition (9) can be written as

$$
\begin{aligned}
& \gamma \leq-G_{w}^{a}\left(p_{a}, w^{* * *}, \rho, \gamma_{1}\right) T+C_{w}^{m}\left(w^{* *}, \rho, \gamma_{1}\right) Y_{m}+ \\
& C_{w}^{s}\left(\mathrm{w}^{* *}, \rho, \gamma_{1}\right) Y_{s},
\end{aligned}
$$

where $\gamma_{1}$ and $\gamma_{2}$ are the labour shock parameters. 